\title{
BECOMING AFRICAN PSYCHOLOGISTS: DECOLONISATION WITHIN A POSTGRADUATE PSYCHOLOGY MODULE AT THE UNIVERSITY OF JOHANNESBURG
}

\author{
N. Joosub \\ Department of Psychology \\ University of Johannesburg \\ Johannesburg, South Africa \\ e-mail: njoosub@uj.ac.za / https://orcid.org/0000-0003-4513-3942
}

\section{ABSTRACT}

There is a compelling need for curriculum design and processes of teaching in South African higher education institutions to heed calls for decolonisation and relevance. Within university Psychology teaching spaces, both the what and the how of knowledge production require transformation and epistemic emancipation. This study explored the perceptions of students regarding the decolonisation processes within a postgraduate Psychology module at the University of Johannesburg. Through the thematic analyses of blogs written by students, results indicated the students benefitted from decolonisation initiatives through three interdependent processes. These processes were (1) Learning Real World Skills from Peers, (2) Bringing it Home: Making Psychology Relevant, and (3) Becoming African Psychologists. Academics in higher education institutions have an ontoepistemological responsibility to encourage students to be critical of the hegemony of Western imperialist forms of knowledge. Therefore, decolonisation initiatives should include students becoming agentic actors who chart the course of their learning processes. Critical thinking skills may facilitate the formation of identities that increase students' agency and creativity within traditionally rigid and hierarchical academic structures.

Keywords: decolonisation, Psychology, active learning, epistemological resistance

"We must be decisive in constructing insurgent scholarship that is truthful, brave, imaginative, and idealistic" (Castillo 2017, 447).

\section{INTRODUCTION}

The academic discipline of Psychology traces its roots to Western notions of modernity that privilege Eurocentric values and practices, such as individualism, heteropatriarchy, and the objectivity of scientific endeavours (Dudgeon, and Walker 2015, 282). Western paradigms of Psychology tend to deny, silence, or assimilate alternative forms of knowledges that do not conform to Western values (Groot, Grice, and Nikora 2018, 216).

The acknowledgement that Psychology and science are produced as situated knowledges has allowed for the critical interrogation of existing frames of academic endeavour and 
decolonising praxis (Mignolo 2009, 167). However, in South Africa, the psychosocial, economic and structural inequalities that were fostered during apartheid are still prevalent in institutions of higher education today (Le Grange 2016, 8). Therefore, the \#FeesMustFall protests in 2015 emphasised the necessity of reforming the curricula in South African universities, to ensure deeper and more authentic transformation processes within these institutions (Ebrahim 2018, 366).

An enduring legacy of colonialism is that, internationally, most psychological research still originates from countries that are Western, Educated, Industrial, Rich, and Developed (WEIRD) (Heleta 2016). However, Frantz Fanon (Fanon 1963, 316), an early activist for decolonisation, urged those in previously colonised settings, such as South Africa, to "invent" and "make discoveries" in order not to fashion themselves after Europe. It is challenging to advocate for the relevance of indigenous knowledge in a context where teaching and learning materials are overwhelmingly neoliberal and WEIRD (Maseti 2018, 344). The problematic assumption that researchers in WEIRD contexts are objective and value-free, and that the knowledge they generate is universal, needs to be challenged in higher education institution contexts (Mignolo 2009, 160). Western notions of capitalism and neoliberalism often result in commodified versions of Psychology that prioritise individualism and profit (Groot, Grice, and Nikora 2018).

Despite increasing awareness of the need to decolonise academic Psychology, discrimination persists. For example, Rad, Martingano, and Ginges $(2018,11402)$ found that articles from the journal Psychological Science were still overwhelmingly produced in Englishspeaking and Western countries, such as North America, Europe, and Australia. Regions that were underrepresented in terms of samples in these articles were Africa, the Middle East and Latin America. This led the authors to conclude that a large proportion of the published research from Psychology, that claims to be universal and generalisable, is based on a small, biased, and unrepresentative sample of the world's population. Another finding from the Rad, Martingano, and Ginges $(2018,11404)$ analysis was that most studies analysed had little information about the culture, ethnicity, socioeconomic status, and regions of the populations that were sampled. This lack of acknowledgement of contextual variables reflects the assumption that Western norms should be accepted as universal (Bulhan 2015, 242).

By prescribing colonial sources to students without encouraging critical reflection, South African academics are complicit in coloniality and epistemic colonisation, which is the belief of the superiority of Eurocentric worldviews (Bulhan 2015, 250; Kessi, and Boonzaier 2018, 305). The individualism, victim-blame and power-relations inherent in Eurocentric psychology are antithetical to community wellbeing (Kiguwa, and Segalo 2018, 311). By reinforcing 
epistemic colonisation in their teaching, South African academics perpetuate colonial scripts of psychological knowledge (Lau 2017, 442). The commercialisation of academia has ensured that particular voices remain dominant within Psychology, particularly those from more affluent and Western regions (Rad, Martingano, and Ginges 2018, 11405). Even within non-Western contexts, neoliberal and Western funding ensures the perpetuation of these injustices (Makkawi $2017,483)$.

While one cannot avoid the scientific dominance of Western research internationally, it is important to question its universal relevance (Bulhan 2015, 253). Due to the availability of research funding and resources being situated in WEIRD contexts, research from diverse contexts is overlooked or undermined as not scientifically rigorous enough. This systemic inequality exposes Psychology students in South Africa to a dominant narrative of Western science as universal, without allowing them to question it due to their own lack of status and intersectionality within these hierarchical academic frameworks (Dudgeon, and Walker 2015, 280). A colonial discourse that did not end with apartheid in South Africa was the intellectual superiority of the coloniser (Mignolo 2009, 179). Within this discourse, the colonised is the passive recipient of the superior knowledge and technology of the coloniser (Heleta 2016, 4). This colonial hegemony is seeped into institutional culture at South African higher education institutions (Prinsloo 2016, 166).

The majority of students at the University of Johannesburg are Black African (79.2\%) (Van Zyl 2016, 3). Higher education in South Africa has been slow to respond to the rapidly changing demographics of students in the post-apartheid era where previously during Apartheid majority of the students were White and had European ancestry (Ammon 2019, 250). Within South African tertiary institutions, the uncritical consumption of Western psychological knowledge results in the production of students who are not equipped to serve the communities and societies in which they live (Ally, and August 2018, 358). These students may not believe in the veracity and relevance of their own lived experiences due to internalised coloniality (Maseti 2018, 343). In addition to internalised coloniality, the Western values of individualism and free choice blind students to the systemic and structural causes of pathology and illness that are ignored in mainstream Psychology (Bulhan 2015, 251).

Decolonisation and curriculum reform require epistemic disobedience and a shift away from the West as the centre of knowledge towards actively addressing local inequalities and challenges (Knight 2018, 272). This reform also requires an interrogation and disruption of the power dynamics inherent in colonial epistemology (Morreira 2017, 291). Curriculum reform is a necessary component of decolonisation where subaltern epistemic knowledge should be promoted (Winberg, and Winberg 2017, 248). 
Carolissen et al. $(2017,500)$ describe the decolonial turn in Psychology as a deliberate displacement of hegemonic Western sources of knowledge by the privileging of local voices and everyday knowledges. This is significant in a post-Apartheid world where plurality and tolerance should be advocated (Knight 2018, 284). Curriculum reform in a decolonial era cannot be separated from the politics of representation and epistemic openness (Leonardo 2018, 8). Africa should be at the centre of this epistemological shift (Prinsloo 2016, 165).

A deeper level of decolonisation is not just the content of the curriculum but also the method or process of implementing curriculum change. The focus on curriculum reform is superficial if not accompanied by more substantial transformations in pedagogy (Ammon 2019, 252). Students are developing a resistance towards the hierarchical academic structures inherited from colonial systems of education (Knight 2018, 283). Didactical pedagogical methods undermine learners' natural needs for curiosity and autonomy in the educational process (Collett et al. 2018, 583). Therefore, active learning tasks, such as flipped classrooms, are important to undermine discourses of the lecturer as expert.

Active learning refers to students being self-directed and actively engaging with material independently (Beyleveld, De Villiers, and Fraser 2019, 20). Flipped classrooms involve students engaging with the material by themselves and then presenting it during class time to demonstrate their skills (Murillo-Zamorano, López Sánchez, and Godoy-Caballero 2019, 2). This allows for students to develop skills that may be needed in the workplace with scaffolding of knowledge facilitated by the lecturer in a student-centred manner.

Liberation psychology calls for researchers in non-WEIRD contexts to use research as an emancipatory tool by privileging the everyday experiences of their people. The power dynamics present in South African higher education institutions reflect discriminatory historical discourses where the lecturer is seen as the active expert and the student the passive, unquestioning, recipient (Reid 2019, 78). However, academic institutions should strive to be discursive spaces where oppressive or discriminatory epistemologies such as those mentioned above are challenged and revolutionised (Kiguwa, and Segalo 2018, 311).

Complementary to the aims of liberation psychology, this study aimed to privilege the voices of students at the University of Johannesburg within a traditionally hierarchical space, the academic institution, and to disrupt students' internalised coloniality through active learning tasks.

\section{METHODS}

The conceptual framework of this study was rooted in a critical decolonised activist methodology which encourages active resistance to reductionist epistemologies and forms of 
research (Adams et al. 2015, 220). Decolonised methodologies incorporate indigenous research ethics, which are committed to social justice and advancing equity (Denzin 2009, 140). Further, they promote bottom-up approaches which privilege voices and narratives that are marginalised (Bulhan 2015, 239). This study qualitatively explored Psychology students' perceptions on decolonisation processes within a postgraduate Psychology module at the University of Johannesburg.

Students were purposively sampled from a postgraduate Psychology module where a systematic process of decolonising knowledge was emphasised. In this module students had to prepare group seminars critiquing the knowledge disseminated in the prescribed textbook, which was produced in the United States of America (USA) and contained primarily concepts and experiences from the developed and Western world. Further, students were encouraged to discuss sources that were produced within South African and African contexts in their seminars. By positioning students as the facilitators of group seminars, the trope of students as passive recipients was disrupted in favour of students driving their own learning processes.

After the seminars had been presented, students were invited to write a blog on their experiences of engaging with decolonisation initiatives within the module. Blogs were chosen as a method of expression due to the freedom they allow for students' reflexivity. Critical pedagogy refers to teaching and research methods that analyse and resist dominant and hegemonic forms of knowledge production (Reid 2019, 89). Storytelling is one form of decolonised research methodology that allows for marginalised voices to be prioritised and given space in traditionally exclusivist spaces (Barnes 2018, 380). Encouraging students to reflect and share their stories in blogs is a bottom-up approach to research where those who have been marginalised are awarded the space to be heard (Bulhan 2015, 245).

Of the 37 students registered for the module, 33 chose to write blogs on their experiences. These students provided voluntary informed consent and the study received ethical approval from the Faculty of Humanities Research Ethics Committee at the University of Johannesburg (REC-01-049-2019). Blogs were written between April and June 2019. The text of the blogs was thematically analysed by the researcher according to the steps described by Braun and Clarke (2006). In the first step the researcher familiarised herself with the data. Once this was completed, the researcher generated initial codes. In the third step, the researcher embarked on an interpretive analysis and searched for themes. Next, the researcher reviewed and refined her themes. Once this process was completed, the researcher defined and named the themes. Lastly, the researcher produced her report where the themes are made sense of in light of existing literature.

An important concept in qualitative research to ensure credibility and trustworthiness is 
that of the researcher's reflexivity (Creswell 2014, 135). Within this study I was the principal investigator, the participants' lecturer and myself a recipient of colonial Psychology education. Navigating these different roles required bracketing and a level of engagement which were facilitated through a reflexive journal.

\section{RESULTS}

Students expressed three main processes within the text of the blogs: (1) Learning Real World Skills from Peers, (2) Bringing it Home: Making Psychology Relevant, and (3) Becoming African Psychologists.

\section{Learning real world skills from peers}

Many of the students described initial apprehension at having to work in groups to present the seminars and to discuss academic material in front of an audience of peers. However, they also expressed that once they had started interacting in a group they found the experience to be fun, empowering, and informative. The tasks of presenting seminars and critiquing the textbook encouraged active learning, increased accountability over the process of learning and deeper engagement with the content. Although students found the task of presenting to peers daunting initially, many students then enjoyed the opportunity of applying their knowledge and interacting with their peers:

"All these feelings of anxiety and fear ultimately bore a great, fruitful and informative experience. Preparing for the presentation was a process that was not only informative and educative, but really fun and eye-opening". (B2).

"As I was preparing for my presentation my eyes were opened for the first time in four years of being in the university as I was reading along and gathering information." (B3).

"Upon receiving the news that we are now presenting the content to our lecturer and fellow students, I must admit it was a bit overwhelming ... I realised that this is actually an opportunity for me to customise the content I got from the textbook, journals and other academic sources and also come out of my shell in preparation for the world outside these University walls." (B4).

"However, after doing research and actually engaging in the material related to my topic I found myself becoming more and more interested. My group and I were able to critically look at the textbook and discover various South African sources relating to the concepts in the textbook with ease." (B5).

The interrelatedness in learning from and with peers disrupts neoliberal and individualist discourses of learning where competition and individual achievement are emphasised (Carolissen et al. 2017, 495). This is an example of dialogical education where students determine their own learning processes through being actively involved (Makkawi 2017, 
486). The flipped classroom allows students to develop skills needed in the workplace such as applying theory, group work, negotiating others' opinions, learning independently, and analysing information (Murillo-Zamorano, López Sánchez, and Godoy-Caballero 2019, 4).

By being allowed the freedom to chart their own course of learning, students realised the power of their own voices:

"The teaching methods we were exposed to previously gave us an impression that education is a one-way stream which means that the teachers were the only people who were able to pass the knowledge to the students. But this module changed the way I see education and also it has changed the way I see psychology." (B8).

"One ends up being more involved in their own course and power dynamics shift considerably in that, all the control is given to the student ... we as students end up feeling more liberated and emancipated by our own learning." (B14).

"We are used to being lectured by adult lecturers and I must say that listening to my peers not only made the seminars interesting but very insightful as we heard and saw how other students' critiquing skills were." (B27).

"Gives us as student a voice, an opinion about issues we face on a daily basis." (B4).

Through the student-led seminars, unequal power relations in the classroom were destabilised with the benefit of allowing students to realise the importance of trusting their own thinking processes, a key component of decolonisation (Lau 2017, 450). The experience of having to deconstruct and critically analyse textbook challenged students to increase their self-confidence and learn new skills:

"For weeks we put our hearts and souls into making this an interesting topic for everyone." (B5).

"I got to learn different perspectives to neuroscience, refine my public speaking and/or presentation skills and of course meet new people with a different background from mine." (B2).

"Not only did the seminar presentations change the way we think but it also enhanced our public speaking skills even though some of us were nervous because we have never presented before." (B8).

The cultural diversity present within their class, and therefore within the presentations, enhanced students' experiences of the seminars. Hegemonic discourses on Psychology emphasise Western concepts as universal and therefore undermine alternative African epistemologies (Carolissen et al. 2017, 496). Decolonisation of the mind requires an active resistance to hegemonic knowledge sources (Adams et al. 2017, 533), and a greater awareness of social contributors to discrimination and injustice (Kessi, and Boonzaier 2018, 300):

"Different groups presenting on different topics, applying it differently to their different cultures 
and beliefs makes it even more interesting." (B4).

"As our classroom population consists of people from various cultural backgrounds, I found each group's presentations extremely informative as it gave me an opportunity to learn from the experiences of others and gain a holistic understanding of the intricacies of the South African culture." (B9).

"Class discussions were extremely informative. What I found to be really interesting was how different students (based on their gender, age, ethnicity, etc.) had differing opinions and views regarding the content." (B12).

"Previous bias and prejudice that I had has been wiped out because of my contact with the different races and hearing their side of interpretations and how they experience life in their families." (B16).

Students found the shift in power dynamics, where they became active in their own learning processes, increased their engagement with their peers and improved skills that would perhaps assist them when they enter the workplace. This newfound experience of power was enlightening and encouraged students to question repressive academic practices which they had experienced in the past.

\section{Bringing it home: Making psychology relevant}

The theme of Bringing it Home emphasised how students applied concepts to their lived experiences and prioritised the South African and African conceptualisations. Through increased awareness of the Western bias in academic Psychology, students realised the need to make Psychology more relevant to themselves and their own contexts. By awarding recognition to the interconnectedness between people and their contexts, Psychology resists Western notions of individualism and separateness (Groot, Grice, and Nikora 2018):

"Our prescribed readings are more often than not produced in Western countries. It is therefore difficult to assume that these textbooks capture the cultural complexity of South Africa." (B9).

"We become so used to only thinking through a Western perspective because that is the context of our textbook, social media and the news." (B11).

"Psychology is a Western discipline but with my fellow colleagues we were able to bring it home by discussing things like historical backgrounds, culture, lobola and black tax." (B8).

This awareness and recognition of different ecologies of knowledge is integral to the decolonisation of Psychology (Carolissen et al. 2017, 501). Students experienced the affirmation and promotion of South African and African knowledge to be empowering, as throughout their university careers Western ideas of Psychology have been unquestioningly accepted as universal. By perpetuating discourses of universality, Western Psychology attempts 
to render culture and context invisible (Macleod 2018). The contextual congruence inherent in decolonial pedagogy improves students' motivation, engagement and even performance in the classroom (Mangcu 2016, 56). Through the process of bringing it home, students challenged the trope that Western Psychology is objective and asocial through exposing the importance of sociocultural influences:

\begin{abstract}
"Most educational resources reflect on the experiences of Western countries, limiting students from developing countries to acquire knowledge which is relevant within their context." (B15).

"It was very interesting and empowering to hear classmates of different cultures and backgrounds interpreting the theoretical content in a way that is applicable to our South African contexts, showing that it is possible and even more necessary to do so." (B23).

"One example that stood out for me was the Westernised perception of the aged/elderly. The language that the textbook used to describe the elderly made them seem like liabilities and rather burdensome to their families and loved ones. Upon reading South African articles, it was apparent, especially in more rural settings, just how respected and valued their aged/elderly were. The grandkids would respect their grandparents more than any other person in the house, regardless of ability or physical weakness." (B31).
\end{abstract}

Students invested time and effort into increased awareness of the context of research they presented in seminars. Macleod $(2018,373)$ advocates for South African students to prioritise South African and African research in their learning processes. Further, one of the benefits of decolonial pedagogy is equipping learners to develop innovative applications to respond to local challenges (Winberg, and Winberg 2017, 248):

"The theories put forward in the textbook cannot be applied to the majority of South Africans." (B32).

"When doing my own research on the topic at hand, not from the textbook, but rather from South African (or African) journals, I was able to see more and more areas where the textbook's Westernised ideas were not just inaccurate, but completely contrary to the South African context." (B31).

"This forced us to all look further than what the West supplied us with and take it apart to look at its relevance in our lives." (B1).

Some students challenged the knowledge in the textbook by countering it with examples from their own or communities' lives. By including community experiences within an academic setting, indigenous knowledge gains legitimacy and allows for disruption of epistemic coloniality. Local history and ecological conditions are reflected better in lived experiences than in Western textbooks (Adams et al. 2017, 533): 
"We can draw from our everyday experiences on how people react and deal with certain situations in order to help us understand better." (B15).

"During my presentation I used a lot of stories to bring a point across and people were very attentive because of the stories. I also shared a lot of my personal experiences that relate to the content in order to better understand the content in the South African context and decolonise Psychology." (B27).

Where African or South African sources could not be found in academic databases, some students took the initiative of interviewing people in their community about relevant concepts. This demonstrated a level of proactivity and responsibility that went beyond that expected in the course outcomes:

"The reason behind interviewing people is due the fact (sic) that there was a challenge in finding the sources or articles in the South African context." (B17).

"Many individuals interviewed locals and came up with scenarios alluding to the thoughts on decolonisation." (B13).

Students included local concepts in their presentations, such as lobola, witchcraft, and black tax. This made them engage theoretically on concepts that had real-world significance for them:

\begin{abstract}
"In my group's presentations, it was made clear that relationships cannot be understood universally either, because relationships are different in different cultures, for example, lobola would not be understood universally, nor could it be compared to the beliefs and values of Western countries." (B13).

"It has been said that growing up in a township requires certain type (sic) of intelligence in order to get through the brutal, busy lifestyle lived. And to my surprise how people from my township defined intelligence might have been different to how my teachers defined it." (B15).

"I confronted my own views and wondered "why do I think it is not important for our voice to be heard, for our own experiences to be conveyed other than applying Western theories to us as Africans when there are so many differences that we possess'." (B26).
\end{abstract}

In the seminars, students were given the space to debate with material that was previously seen as objective and infallible. Through this process they realised that the knowledge from their own communities may be more relevant than foreign colonial knowledge. This increased questioning and critical thinking laid the foundation for a holistic process discussed in the last theme: an identity based on becoming African psychologists.

\title{
Becoming African psychologists
}

Becoming African Psychologists expresses a shift beyond just indigenisation of the coloniality 
of knowledge. It implies an active resistance to, and deconstruction of the coloniality of being, as students discussed an emerging identity based on becoming African Psychologists who need to take the decolonisation of Psychology forward. This recentreing of identities towards an acknowledgement of Africanness and displacement of the rhetoric of colonial superiority is a deeper form of decolonisation due to curriculum reform (Prinsloo 2016). Affirmative social identities are powerful catalysts for political and social change (Kessi. and Boonzaier 2018, 301). This theme demonstrated the shift from deficient colonial subject-positions towards proactivity and agency in the students' journeys:

"I didn't initially understand the purpose of allowing students present the course work to the class ... I now realise as we move towards the 4th industrial revolution that there was so much hidden wisdom in it, because we as students are tomorrow's leaders." (B1).

"By being exposed to our own country's perspective, this will aid us in being the best psychologists we can be in South Africa." (B29).

This identity was influenced by the increasing resistance to the epistemic violence and essentialization that is implied in Western normativity, and agreement that this hegemony needs to be actively countered by African psychologists. Conscientisation is a core component of students' subjectivities as African Psychologists, and liberates students from being complicit in their own internalised coloniality, oppression and inferiority (Castillo 2017, 447). This awareness of the need for socially just and ethical praxis is central to decolonial pedagogy (Winberg, and Winberg 2017, 249). Becoming African Psychologists described a sense of agency in the self-determination of students' knowledge production (Adams et al. 2017, 539):

"As a society we have relied more on Western perceptions neglecting the fact that each society has different values and priorities and will therefore perceive their environment according to what may be morally right." (B15).

"Personally I enjoyed the seminar experience as it taught me to stop thinking in a one directional manner, and that Western culture and concepts are not the sole source of knowledge." (B5).

Questioning what they had been taught in their undergraduate years fostered a sense of personal engagement and meaning within students' learning processes. This questioning and exploration is part of what Maldonado-Torres $(2017,433)$ terms a "decolonial attitude":

"From the first day of my university career I knew none of the concepts, theories or ideas applied to me as a South Africa Black female. The seminars have opened up a whole new opportunity for me to think differently about psychological theories in this course and any theory that I come across." (B22). 
"Students may often feel alienated when teaching, theory and material revolve around Western ideologies. They are often unable to relate to their work which further alienates them. For students to fully comprehend the theory, they need to feel a sense of relatedness." (B23).

"I can now say I am an African Psychologist in the making. As an undergraduate I never thought I would be talking about witchcraft in psychology. This made me view psychological content in a different light because we spoke on things that one sees and hears about in their everyday life. Western work only required us to imagine things that we either saw in movies or social media but African content is what we experience which makes it easier for understanding and interpretation." (B16).

This decolonial attitude encourages a shift from reductionist Western dependence to selfdetermination and emancipatory knowledge (Makkawi 2017, 490). Therefore, Becoming African Psychologists implied a sense of creative and critical thinking about existing knowledge, and a spirit of resilience. This is in direct contrast to derogatory and deficit-focused representations of Africans propagated by colonial Psychology in the past (Kessi, and Boonzaier 2018, 308). Africanness has systematically been undervalued and undermined in South African higher education institutions (Morreira 2017, 290):

"I was part of the Intelligence group and it was really interesting. We came up with our own word 'Afro-Intelligence' after observing and coming to the realisation that different cultures or even races may define 'intelligence' differently in terms of traditional teachings, cultural systems and beliefs, etc." (B4),

"The way this module was delivered impacted my critical thinking and made me realise that my stay in University has not really taught me much about an African perspective of Psychology." (B16),

"As I read further, I started having some thought provoking questions about all the information I was exposed to. It was at that exact moment when I realised that I am actually engaging in some critical thinking. Most of the information I came across from various Psychology textbooks as well as journal articles, was Western-based which then led to me having questions about cultural considerations, language, gender considerations as well as demographical information and whether all the information I came across is relevant enough to be generalised especially in South Africa since it is such a diverse country." (B21),

"Most stereotypes, especially those surrounding women (mostly Black women), were challenged in a way that proves to the audience that women do not automatically fall under a stereotype and therefore (it) cannot be generalised." (B21),

A sense of activism and the need for the current generation of students to change the discriminatory status quo of Psychology was also expressed. South African students need to critically engage with gaps in existing knowledge to which they can contribute (Macleod 2018, 444):

"Active steps must be taken to make Psychology and therapy accessible to developing countries 
and countries that have a history as harsh as South Africa." (B18).

"I have also realised that Africa and South Africa has a lot of ground to cover when it comes to knowledge production that resonates with the ideologies that we, as a country and continent, subscribe to and that also takes into consideration cultural difference that cannot be ignored." (B22)

"By decolonising Psychology, we are able to strengthen our own influence as South Africans and expand our knowledge that will be more applicable to our own context." (B23).

"Looking at African problems from an African perspective will surely lead to solutions fit for African nations." (B24).

“And the West won't find theories for us, it is up to us, starting with the students at UJ, to work on our own applicable theories and independence. More so in the Humanities such as Psychology where we work with lived experiences and how that shape us as human beings." (B24).

Through viewing themselves as active agents in shaping the course of Psychology in South Africa and Africa, students embraced the identity of African psychologists as one that is proactive and revolutionary. This emancipatory attitude could facilitate their active contributions to further decolonising research and praxis in Psychology.

\section{DISCUSSION}

The active learning tasks in this module allowed students to be actively engaged in their learning and to apply their own understandings to existing knowledge. This laid the necessary foundation needed for them to be aware of the fallibility of Western knowledge and work to contribute to more ecological forms of knowledge (Macleod 2018, 378). The collaborative method of teaching in this module allowed for the disruption of hierarchical power relations within the classroom. Dominant practices of colonial knowledge production alienate students and do not allow for deeper engagement and critique (Groot, Grice, and Nikora 2018). The transformation and enlightenment inherent in learning from peers was a major impetus to facilitating the development of critical thinking within this module.

Learning Real World Skills from Peers directly challenged tropes about modules in the Humanities not being applied enough as students expressed having improved skills that may assist them in the workplace. Further, the teamwork and collaborative modes of learning allowed them to apply soft skills such as negotiation of work and interdependence. Students found their experiences of interrelatedness and collaborative learning to be a valuable resource in facilitating their engagement. Cultural diversity and teamwork were associated with improved critical and analytical skills within the flipped classroom.

The process of Bringing it Home: Making Psychology Relevant represented a form of indigenisation of Psychology where local concepts and understandings were incorporated into 
existing Western psychological ideas. By acknowledging local contexts in their conceptualisations, students acknowledged the interconnectedness of people and their environments. Through privileging local and community knowledge over the colonial knowledge in the textbook, students shifted their trust from Western knowledge to knowledge that is more relevant to their everyday lives. This led to an active resistance to hegemonic discourses allowing for a decolonial turn in students' epistemologies.

Becoming African Psychologists as a process reflects a shift in students' epistemological development beyond indigenisation towards a radical rethinking of Psychology as a discipline. This theme represents a shift from the coloniality of knowledge towards the coloniality of being (Adams et al. 2017, 536). Students expressed agency and activism in their roles as psychologists, committed to the decolonisation of their discipline and acknowledged that this requires advocating for a critical and emancipatory praxis of Psychology.

\section{CONCLUSION}

South African Psychology students will struggle to advocate for indigenous and African epistemologies if they are not encouraged to think critically and trust their own voices (Kiguwa, and Segalo 2018, 315; Waghid 2009, 848). Within the current tertiary education system, Western hegemony alienates and devalues the lived experience of students. Discourses on decolonisation advocate the alternative narrative that students in African contexts have agency and can influence the framing and future of Psychology in this context (Heleta 2016, 2).

By not actively advocating for and participating in decolonisation processes, academics are practicing a form of epistemic violence that does a disservice to students in particular, and to the transformation process more broadly. What we teach needs to change, but also how we teach needs to challenge normative and hierarchical notions of teacher and student. Students need to be encouraged to become agentic in learning endeavours and benefit from dialogical education initiatives through a deeper engagement with academic material and their peers. Decolonising processes are lifelong as psychologists react to present circumstances with continuous reflexivity and shifts in awareness, and the earlier students learn to become selfand other-reflexive, the more powerful these shifts can be.

Educational implications of this decolonial turn would be a complete disruption of colonial power dynamics and subject-positions inherited from a bygone era. This implies that the university will become a pluriversity (Morreira 2017, 290) and that the students' knowledge is privileged, as the student comes from a certain epistemological framework that influences their pedagogical engagement. Academics can no longer enjoy the imperial privileges of universities' hierarchical colonial heritage, they will need to work as much as the students on 
engagement and attunement.

Within the Psychology curriculum, the decolonial turn implies moving away from tropes that Western psychology is an objective science, and towards acknowledging the discriminatory imperialist past of Psychology and its problematic applications within South Africa and beyond. This intrapersonal and interpersonal interrogation is not easily achieved, however is necessary for academics to lead by example in their counter-hegemonic efforts. Structural power relations, sociohistorical influences, and epistemological dominance need to be explicitly uncovered within the academy, and be acknowledged where they exist in the curriculum (De Oliveira Andreotti et al. 2015, 26).

By awarding dominance to the voices and opinions of students, this study aimed to expand understandings of Psychology from its reductionist focus on the work of specific knowledges situated within privilege and discrimination towards more grounded and relevant knowledges. These knowledges can then in turn become the lived curriculum of decolonised Psychology which emphasises bottom-up and grounded approaches (Kiguwa, and Segalo 2018, 317). It is necessary to incorporate these grounded, ecological understandings in order for Psychology to improve its social and political relevance.

\section{REFERENCES}

Adams, Glenn, Ignacio Dobles, Luis H. Gómez, Tuğçe Kurtiş, and Ludwin E. Molina. 2015. "Decolonizing Psychological Science: Introduction to the Special Thematic Section." Journal of Social and Political Psychology 3(1): 213-238. https://doi.org/10.5964/jspp.v3i1.564.

Adams, Glenn, Luis Gómez Ordóñez, Tuğçe Kurtiş, Ludwin E. Molina, and Ignacio Dobles. 2017. "Notes on Decolonizing Psychology: From One Special Issue to Another." South African Journal of Psychology 47(4): 531-541. https://doi.org/10.1177/0081246317738173.

Ally, Yaseen, and Justin August. 2018. "\#Sciencemustfall and Africanising the Curriculum: Findings from an Online Interaction." South African Journal of Psychology 48(3): 351-359. https://doi.org/10.1177/0081246318794829.

Ammon, Linnéa. 2019. "Indigenising the University Curriculum in Southern Africa." Indigenous Studies, 243-254. https://doi.org/10.4018/978-1-7998-0423-9.ch013.

Barnes, Brendon R. 2018. "Decolonising Research Methodologies: Opportunity and Caution." South African Journal of Psychology 48(3): 379-387. https://doi.org/10.1177/0081246318798294.

Beyleveld, M., J. J. R. de Villiers, and W. J. Fraser. 2019. "The Use of Active Learning in a Private Higher Education Institution: The Lecturer's Perspective." South African Journal of Higher Education 33(2): 16-28. https://doi.org/10.20853/33-2-2804.

Braun, Virginia, and Victoria Clarke. 2006. "Using Thematic Analysis in Psychology." Qualitative Research in Psychology. https://doi.org/10.1191/1478088706qp063oa.

Bulhan, Hussein A. 2015. "Stages of Colonialism in Africa: From Occupation of Land to Occupation of Being." Journal of Social and Political Psychology 3(1): 239-256. https://doi.org/10.5964/jspp.v3i1.143.

Carolissen, Ronelle, Hugo Canham, Eduard Fourie, Tanya Graham, Puleng Segalo, and Brett Bowman. 2017. "Epistemological Resistance towards Diversality: Teaching Community Psychology as a Decolonial Project." South African Journal of Psychology 47(4): 495-505. 
https://doi.org/10.1177/0081246317739203.

Castillo, Fatima Alvarez. 2017. "Consciousness: The Arena of Struggle Today: Response to 'Frantz Fanon and the Decolonial Turn in Psychology: From Modern/Colonial Methods to the Decolonial' Attitude by Nelson Maldonado-Torres." South African Journal of Psychology 47(4): 446-447. https://doi.org/10.1177/0081246317738179.

Collett, K. S., B. von der Heyden, R. W. M. Pott, and J. Stander. 2018. "A Collaborative AutoEthnographic Exploration of Socially Just Practices by New Academics in Two South African Higher Education Institutions." South African Journal of Higher Education 32(6): 582-603. https://doi.org/10.20853/32-6-2983.

Creswell, J. W. 2014. Research Design: Qualitative, Quantitative and Mixed Methods Approaches. New York: Sage Publications.

De Oliveira Andreotti, Vanessa, Sharon Stein, Cash Ahenakew, and Dallas Hunt. 2015. "Mapping Interpretations of Decolonization in the Context of Higher Education." Decolonization: Indigeneity, Education \& Society 4(1): 21-40.

Denzin, Norman K. 2009. "The Elephant in the Living Room: Or Extending the Conversation about the Politics of Evidence." Qualitative Research 9(2): 139-160. https://doi.org/10.1177/ 1468794108098034 .

Dudgeon, Pat, and Roz Walker. 2015. "Decolonising Australian Psychology: Discourses, Strategies, and Practice." Journal of Social and Political Psychology 3(1): 276-297. https://doi.org/ 10.5964/jspp.v3i1.126.

Ebrahim, Sumayya. 2018. "Villains and Victors: Representations of the Fallists in Newspapers during the 2015 University Crisis." South African Journal of Psychology 48(3): 360-371. https://doi.org/10.1177/0081246318790924.

Fanon, Frantz. 1963. The Wretched of the Earth. New York: Grove Press.

Groot, Shiloh, Jade Le Grice, and Linda Waimarie Nikora. 2018. "Indigenous Psychology in New Zealand." In Asia-Pacific Perspectives on Intercultural Psychology, 198-217. Oxfordshire: Routledge. https://doi.org/10.4324/9781315158358-11.

Heleta, Savo. 2016. "Decolonisation of Higher Education: Dismantling Epistemic Violence and Eurocentrism in South Africa." Transformation in Higher Education 1(1): 1-8. https://doi.org/ 10.4102/the.v1i1.9.

Kessi, Shose, and Floretta Boonzaier. 2018. "Centre/Ing Decolonial Feminist Psychology in Africa." South African Journal of Psychology 48(3): 299-309. https://doi.org/10.1177/ 0081246318784507.

Kiguwa, Peace, and Puleng Segalo. 2018. "Decolonising Psychology in Residential and Open Distance E-Learning Institutions: Critical Reflections." South African Journal of Psychology 48(3): 310 318. https://doi.org/10.1177/0081246318786605.

Knight, Jasper. 2018. "Decolonizing and Transforming the Geography Undergraduate Curriculum in South Africa." South African Geographical Journal 100(3): 271-290. https://doi.org/10.1080/ 03736245.2018.1449009.

Lau, Ursula. 2017. "Storylines in Psychology: Rewriting or Rehearsing Colonial Scripts? Response to 'Frantz Fanon and the Decolonial Turn in Psychology: From Modern/Colonial Methods to the Decolonial Attitude' by Nelson Maldonado-Torres." South African Journal of Psychology 47(4): 442-445. https://doi.org/10.1177/0081246317738176.

Le Grange, L. 2016. "Decolonising the University Curriculum: Leading Article.” South African Journal of Higher Education 30(2): 1-12.

Leonardo, Zeus. 2018. "Dis-Orienting Western Knowledge.” The Cambridge Journal of Anthropology 36(2): 7-20. https://doi.org/10.3167/cja.2018.360203.

Macleod, Catriona Ida. 2018. "The Case for Collation to Inform Debate and Transform Practice in Decolonising Psychology." South African Journal of Psychology 48(3): 372-378. https://doi.org/ $10.1177 / 0081246318784508$. 
Makkawi, Ibrahim. 2017. "The Rise and Fall of Academic Community Psychology in Palestine and the Way Forward." South African Journal of Psychology 47(4): 482-492. https://doi.org/ $10.1177 / 0081246317737945$.

Maldonado-Torres, Nelson. 2017. "Frantz Fanon and the Decolonial Turn in Psychology: From Modern/Colonial Methods to the Decolonial Attitude." South African Journal of Psychology 47(4): 432-441. https://doi.org/10.1177/0081246317737918.

Mangcu, Xolela. 2016. "DECOLONIZING SOUTH AFRICAN SOCIOLOGY: Building on a Shared 'Text of Blackness'." Du Bois Review 13(1): 45-59. https://doi.org/10.1017/ S1742058X16000072.

Maseti, Thandokazi. 2018. "The University Is Not Your Home: Lived Experiences of a Black Woman in Academia." South African Journal of Psychology 48(3): 343-350. https://doi.org/10.1177/ 0081246318792820 .

Mignolo, Walter D. 2009. "Epistemic Disobedience, Independent Thought and Decolonial Freedom." Theory, Culture \& Society 26(8): 159-181. https://doi.org/10.1177/0263276409349275.

Morreira, Shannon. 2017. "Steps Towards Decolonial Higher Education in Southern Africa? Epistemic Disobedience in the Humanities." Journal of Asian and African Studies 52(3): 287-301. https://doi.org/10.1177/0021909615577499.

Murillo-Zamorano, Luis R., José Ángel López Sánchez, and Ana Luisa Godoy-Caballero. 2019. "How the Flipped Classroom Affects Knowledge, Skills, and Engagement in Higher Education: Effects on Students' Satisfaction." Computers and Education 141(June). https://oi.org/10.1016/ j.compedu.2019.103608.

Prinsloo, Estelle H. 2016. "The Role of the Humanities in Decolonising the Academy." Arts and Humanities in Higher Education 15(1): 164-168. https://doi.org/10.1177/1474022215613608.

Rad, Mostafa Salari, Alison Jane Martingano, and Jeremy Ginges. 2018. "Toward a Psychology of Homo Sapiens: Making Psychological Science More Representative of the Human Population." Proceedings of the National Academy of Sciences of the United States of America 115(45): 11401-11405. https://doi.org/10.1073/pnas.1721165115.

Reid, Robin E. 2019. "Intercultural Learning and Place-Based Pedagogy: Is There a Connection?" New Directions for Teaching and Learning 2019(157): 77-90. https://doi.org/10.1002/t1.20331.

Van Zyl, Andre. 2016. "The Contours of Inequality: The Links between Socio-Economic Status of Students and Other Variables at the University of Johannesburg." Journal of Student Affairs in Africa 4(1). https://doi.org/10.14426/jsaa.v4i1.141.

Waghid, Y. 2009. "Initiating Debate: Towards a Cosmopolitan African University." South African Journal of Higher Education 23(5): 845-851. https://doi.org/10.4314/sajhe.v23i5.48803.

Winberg, Simon, and Chis Winberg. 2017. "Using a Social Justice Approach to Decolonize an Engineering Curriculum.” IEEE Global Engineering Education Conference. EDUCON April: 248-254. https://doi.org/10.1109/EDUCON.2017.7942855. 